Check for updates

Cite this: RSC Adv., 2018, 8, 38

Received 22nd August 2017

Accepted 28th November 2017

DOI: $10.1039 / \mathrm{c} 7 \mathrm{ra09299g}$

rsc.li/rsc-advances

\section{Facile surface modification of nickel ferrite nanoparticles for inherent multiple fluorescence and catalytic activities}

\author{
Souvanik Talukdar, (DD *a Rupali Rakshit, (D) ab André Krämer, ${ }^{c}$ Frank A. Müller ${ }^{c}$ \\ and Kalyan Mandal ${ }^{a}$
}

\begin{abstract}
We synthesized biocompatible $\mathrm{NiFe}_{2} \mathrm{O}_{4}$ nanoparticles (NPs) with diameters below $10 \mathrm{~nm}$ by coating their surface with a tartrate ligand, which interestingly give rise to photoluminescence covering the entire visible region. The analyses with various spectroscopic tools reveal that the reason behind the unique fluorescence properties of functionalized $\mathrm{NiFe}_{2} \mathrm{O}_{4} \mathrm{NPs}$ is ligand-to-metal charge-transfer transition from the highest occupied energy level of tartrate ligand to the lowest unoccupied energy level of $\mathrm{Ni}^{2+}$ and $\mathrm{d}-\mathrm{d}$ transitions centered over $\mathrm{Ni}^{2+}$ ions in the NPs. These fluorescent NPs are also found to be suitable for cell imaging. Moreover, the functionalized $\mathrm{NiFe}_{2} \mathrm{O}_{4} \mathrm{NPs}$ show a good catalytic activity on biologically and environmentally toxic pigments, such as bilirubin and methylene blue which leads to their wide application towards therapeutics and waste water treatment. We believe that the developed multifunctional $\mathrm{NiFe}_{2} \mathrm{O}_{4}$ NPs would stimulate the opportunities for advanced biomedical applications.
\end{abstract}

\section{Introduction}

With increasing applications, particularly in biomedical fields, ${ }^{1-5}$ multifunctional magnetic nanoparticles (MNPs) have attracted tremendous attention due to their potential to be used in ultrasound, ${ }^{6}$ optical and fluorescence imaging combined with targeted drug delivery, ${ }^{7-9}$ separation and purification of cells ${ }^{10}$ tissue repairing, ${ }^{11}$ hyperthermia for cancer treatment ${ }^{12}$ as they result from biocompatibility, chemical stability and controlled transport properties. The MNPs are also useful in the field of catalysis since they are efficient for specific chemical transformations. In addition they are propitious economically and environmentally due to their elevated activity, sufficient stability, controlled separation by an external magnetic field, low cost, and facile synthesis. ${ }^{13-19}$

MNPs with intrinsic fluorescence are in high demand. To be used in biomedical fields, they should possess criteria such as biocompatibility, monodispersity, dispersibility in water, and non-toxicity. The commonly used procedure for synthesizing magneto-fluorescent NPs involves processes like making nanocomposites with quantum dots (QDs) or coatings with fluorescent dyes. In order to make the NPs biocompatible,

\footnotetext{
${ }^{a}$ Department of Condensed Matter Physics \& Material Science, S. N. Bose National Centre for Basic Sciences, JD Block, Sector-III, Salt Lake, Kolkata-700106, India. E-mail: souvanik.talukdar@bose.res.in

${ }^{b}$ Indian Institute of Science Education and Research Bhopal, Bhopal Bypass Road, Bhauri, Huzur, Bhopal, 462066, Madhya Pradesh, India

${ }^{c}$ Otto-Schott-Institut für Materialforschung(OSIM), Friedrich-Schiller-Universität Jena, Löbdergraben 32, 07743 Jena, Germany
}

surface modifications were carried out with biomolecules like proteins, DNA, RNA, small organic ligands, and polymers, but none of them were able to generate intrinsic fluorescence. In addition, their applications towards the biomedical field are narrowed due to chemical instability, photobleaching of fluorescent dyes, and inherent toxicity of QDs (due to the presence of heavy metals like $\left.\mathrm{Cd}^{2+}, \mathrm{Pb}^{2+}\right){ }^{20}$ Therefore, to open up a wide applicability of the nanoparticles (NPs) in biomedical field, a facile and proper process for surface modification is highly required. The main purpose of our present work is to design water dispersible 3d transition metal oxide based MNPs with intrinsic fluorescence for their applications in cell imaging.

Our work has involved both the synthesis and development of $\mathrm{NiFe}_{2} \mathrm{O}_{4}$ NPs as multifunctional nano-probes bearing inherent multicolour photoluminescence and their development of in vitro cell imaging. Moreover, we have utilized the developed MNPs in catalysis. Using ligand field theory (LFT), we have assigned the electronic transitions responsible for the coloured photoluminescence of the functionalized $\mathrm{NiFe}_{2} \mathrm{O}_{4}$ NPs. We tried the functionalized NPs as cell imaging agent and found them worthy to be used in imaging applications.

\section{Experiment}

We synthesized $\mathrm{NiFe}_{2} \mathrm{O}_{4}$ NPs with minimal modification, by following a wet chemical method previously reported by Sun et al. ${ }^{21}$ We heated a solution mixture of iron(III) acetylacetonate, nickel(II) acetate, diphenyl ether, oleylamine, and oleic acid to $270{ }^{\circ} \mathrm{C}$ for $1 \mathrm{~h}$ in presence of cetyl alcohol instead of 1,2-hexadecanediol used by Sun et al. ${ }^{21}$ The as-synthesized $\mathrm{NiFe}_{2} \mathrm{O}_{4} \mathrm{NPs}$ 
were then washed by ethanol, and subsequently collected after centrifugation followed by removal of mother solution. Then assynthesized $\mathrm{NiFe}_{2} \mathrm{O}_{4}$ NPs were dried by heating the NPs on a hotplate at a temperature of $80{ }^{\circ} \mathrm{C}$ for $30 \mathrm{~min}$. In order to functionalize the as-prepared $\mathrm{NiFe}_{2} \mathrm{O}_{4} \mathrm{NPs}$ with tartrate ligands, we put the as-prepared solid NPs with $0.5 \mathrm{M}$ Na-tartrate solution $(\mathrm{pH} \sim 7)$ in glass vial. Then the glass vial was placed on a vibrator rotor for vigorous vibration, and the rotation was done at room temperature for $12 \mathrm{~h}$. The non-solubilised $\mathrm{NiFe}_{2} \mathrm{O}_{4}$ NPs were filtered by passing the functionalized NPsolution mixture through a syringe filter of diameter $0.22 \mu \mathrm{m}$. We obtained a clear solution of tartrate-functionalized $\mathrm{NiFe}_{2} \mathrm{O}_{4}$ NPs, called T-NiFe $\mathrm{O}_{4}$ NPs.

The X-ray powder diffraction (XRD) of as-prepared $\mathrm{NiFe}_{2} \mathrm{O}_{4}$ NPs was carried out using Rikagu miniflex II diffractometer equipped with $\mathrm{Cu} \mathrm{K} \alpha$ radiation (at $40 \mathrm{~mA}$ and $40 \mathrm{kV}$ ) at the scanning rate of $3^{\circ}$ per minute in the $2 \theta$ range of $20-70^{\circ}$. A FEI Technai $\mathrm{G}^{2} \mathrm{TF}-20$ field-emission high-resolution transmission electron microscope (TEM), operated at $200 \mathrm{kV}$ was used to study the size distribution, shape, morphology and to record the Energy-dispersive X-ray analysis (EDX) spectrum of the asprepared and functionalized $\mathrm{NiFe}_{2} \mathrm{O}_{4}$ NPs. The ultravioletvisible (UV/Vis) absorbance spectra of $\mathrm{T}-\mathrm{NiFe}_{2} \mathrm{O}_{4}$ NPs were obtained on a Shimadzu UV-2600 spectrophotometer, using a quartz cuvette of $1 \mathrm{~cm}$ path length. A Horiba Jovin Yvon Model Fluorolog fluorimeter was used to carry out the steady-state fluorescence emission and excitation study of T- $\mathrm{NiFe}_{2} \mathrm{O}_{4} \mathrm{NPs}$. Fluorescence micrographs of $\mathrm{T}-\mathrm{NiFe}_{2} \mathrm{O}_{4} \mathrm{NPs}$ were captured using a Leica DM1000 LED fluorescence microscope.

To be sure of the attachment of tartrate molecules to the NPs' surface, Fourier transform infrared spectroscopy (FTIR) measurements were performed using a JASCO FTIR-6300 spectrometer. For FTIR study, pellets were made after homogeneous mixing of lyophilized T- $\mathrm{NiFe}_{2} \mathrm{O}_{4}$ powder samples with $\mathrm{KBr}$. The background was corrected using a reference $\mathrm{KBr}$ pellet. To estimate the loading of the tartrate functionalization, we performed thermogravimetry (TG) on the $\mathrm{T}-\mathrm{NiFe}_{2} \mathrm{O}_{4}$ and bare $\mathrm{NiFe}_{2} \mathrm{O}_{4}$ NPs using PerkinElmer Diamond TG/DTA with the heating rate of $10{ }^{\circ} \mathrm{C} \mathrm{min}{ }^{-1}$. The magnetic measurements were performed using a Lake Shore Vibrating Sample Magnetometer (VSM).

For cell culture tests, cells of the human osteosarcoma cell line Cal-72 were ordered from the DSMZ (Leibniz Institute DSMZ - German Collection of Microorganisms and Cell Culture, DSMZ no. ACC 439). The cells were cultivated in Dulbecco's Modified Eagle Medium with a concentration of $10 \%$ foetal bovine serum. After three days the medium was removed and replaced by mixtures of culture medium and functionalized NPs at concentrations of 6,2 , and $0.5 \mathrm{mg} \mathrm{mL}^{-1}$. After one day those mixtures were removed and the cells were fixed using $3 \%$ paraformaldehyde in Phosphate Buffered Saline (PBS). Cytotoxicity was performed by watching the phenotype and condition of the cells for several hours using a high resolution optical microscope. Images of the cells along with NPs were taken using a Laser Scanning Microscope (LSM).

In the photocatalytic study, an $8 \mathrm{~W}$ UV lamp with a wavelength of $253.7 \mathrm{~nm}$ (UV-C) was used. The aqueous solution of T-
$\mathrm{NiFe}_{2} \mathrm{O}_{4} \mathrm{NPs}$ ( $50 \mu \mathrm{L}$, containing $0.06 \mathrm{mg}$ NPs) and $5 \mu \mathrm{M}$ aqueous solution of methylene blue $(\mathrm{MB})(\mathrm{pH} \sim 3)$ were uniformly mixed in a quartz cuvette for $1 \mathrm{~h}$ in the dark. Then, the cuvette was kept $2 \mathrm{~cm}$ away from the light source and the absorbance spectra of $\mathrm{MB}$ in presence of $\mathrm{T}-\mathrm{NiFe}_{2} \mathrm{O}_{4}$ NPs solution was measured periodically by Shimadzu UV-2600 UV/Vis spectrophotometer. The very first recorded set of data of absorbance was marked as 0 minute. After 60 minutes of irradiation (first cycle), we further added $5 \mu \mathrm{L}$ methylene blue solution to the reaction mixture but the catalyst solution was not added for the second cycle. Similar procedure was maintained up to 5 cycles.

In order to determine the catalytic activity of functionalized $\mathrm{NPs}$, the aqueous solution of T-NiFe $\mathrm{O}_{4} \mathrm{NPs}(50 \mu \mathrm{L}$, containing $0.06 \mathrm{mg}$ NPs) were added to $15 \mu \mathrm{L}$ of aqueous solution of bilirubin $(\mathrm{BR})(\mathrm{pH} \sim 7)$ kept in a quartz cuvette under continuous stirring in the dark. Then the absorbance spectra of $\mathrm{BR}$ in presence of $\mathrm{T}-\mathrm{NiFe}_{2} \mathrm{O}_{4}$ NPs solution were recorded at times by using UV/Vis spectrophotometer. The reusability study was carried out by the similar procedure as we did for photocatalysis up to 3 cycles.

\section{Results and discussion}

The XRD pattern as shown in Fig. 1(a) is consistent with the standard inverse spinel face centered cubic structure of $\mathrm{NiFe}_{2} \mathrm{O}_{4}$ (JCPDS card no. 10-0325). The EDX spectrum of $\mathrm{NiFe}_{2} \mathrm{O}_{4} \mathrm{NPs}$ in the inset of Fig. 1(a) affirms the presence of nickel, iron and oxygen. To obtain the morphology and particle size of assynthesized $\mathrm{NiFe}_{2} \mathrm{O}_{4} \mathrm{NPs}$, we carried out TEM analysis, as shown in Fig. 1(b). From Fig. 1(c), it is apparent that the NPs have a size distribution with an average diameter of $6.8 \mathrm{~nm}$. The high-resolution transmission electron microscope (HRTEM) image, as shown in Fig. 1(d) depicts the highly crystalline nature of the as-prepared $\mathrm{NiFe}_{2} \mathrm{O}_{4}$ NPs. The measured interplanar distance between lattice fringes is around $0.253 \mathrm{~nm}$, which corresponds to the distance between the (311) planes of the $\mathrm{NiFe}_{2} \mathrm{O}_{4}$ crystal lattice.

To make the $\mathrm{NiFe}_{2} \mathrm{O}_{4}$ NPs biocompatible and waterdispersible, we have functionalized the as-prepared NPs with the aqueous solution of a small organic ligand, Na-tartrate. After surface functionalization, the size of the NPs was found to remain almost unchanged with an average diameter of

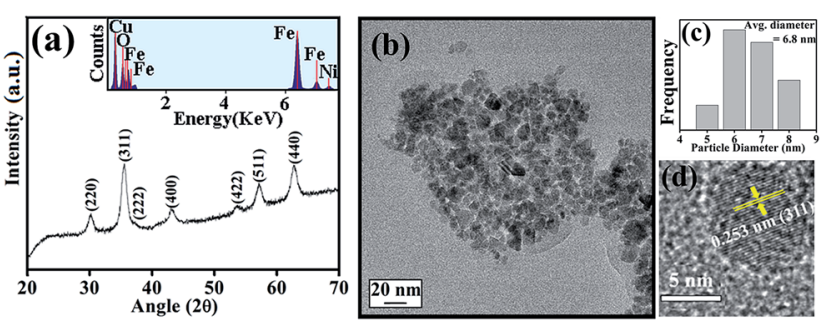

Fig. 1 (a) XRD of the as-prepared bare $\mathrm{NiFe}_{2} \mathrm{O}_{4} \mathrm{NPs}$. Inset of (a) EDX spectrum of the NPs, indicating the presence of only $\mathrm{Ni}, \mathrm{Fe}$, and $\mathrm{O}$. (b) TEM, (c) size distribution graph, (d) HRTEM of as-prepared $\mathrm{NiFe}_{2} \mathrm{O}_{4}$ NPs. HRTEM image shows the crystallinity of the as-prepared $\mathrm{NiFe}_{2} \mathrm{O}_{4}$ NPs. 

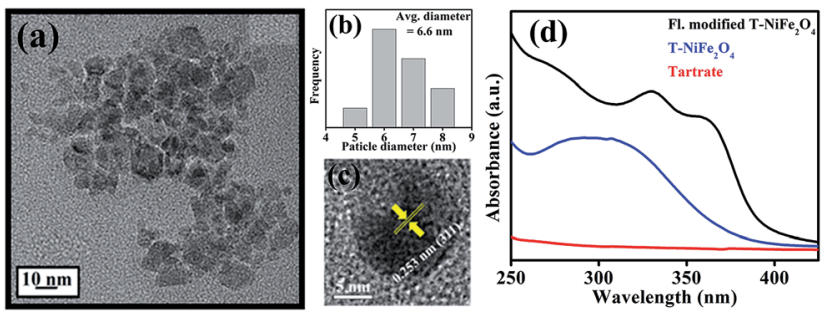

Fig. 2 (a) TEM, (b) size distribution graph, (c) HRTEM of water dispersible $\mathrm{T}-\mathrm{NiFe}_{2} \mathrm{O}_{4} \mathrm{NPs}$, (d) UV/Vis absorption spectra of tartrate, T$\mathrm{NiFe}_{2} \mathrm{O}_{4}$, and fluorescence modified $\mathrm{T}-\mathrm{NiFe}_{2} \mathrm{O}_{4} \mathrm{NPs}$. Size distribution graph depicts that the average particle diameter remains almost unchanged after surface modification.

$6.6 \mathrm{~nm}$, as evident from Fig. 2(a) and the size distribution graph shown in Fig. 2(b). The HRTEM image (shown in Fig. 2(c)) of the functionalized NPs $\left(\mathrm{T}-\mathrm{NiFe}_{2} \mathrm{O}_{4}\right)$ shows its crystalline nature. Interestingly, the UV/Vis absorption spectra of $\mathrm{T}-\mathrm{NiFe}_{2} \mathrm{O}_{4} \mathrm{NPS}$ $(\mathrm{pH} \sim 7)$ is found to exhibit a broad absorption feature at around $302 \mathrm{~nm}$ as shown in Fig. 2(d), indicates that the tartrate ligand affects the surface electronic structure of bare $\mathrm{NiFe}_{2} \mathrm{O}_{4}$ NPs significantly upon functionalization.

After obtaining knowledge from the UV/Vis spectra of functionalized $\mathrm{NiFe}_{2} \mathrm{O}_{4} \mathrm{NPs}$, we have performed a photoluminescence study and have observed photoluminescence at $412 \mathrm{~nm}$ (low intensity) on exciting the sample at wavelength of $325 \mathrm{~nm}$. To intensify the photoluminescence, we have carried out further surface modification by heating the functionalized $\mathrm{NiFe}_{2} \mathrm{O}_{4}$ NPs solution for $42 \mathrm{~h}$ at $70{ }^{\circ} \mathrm{C}$ and $\mathrm{pH} \sim 12$ which we call fluorescence modified (fl. mod.) $\mathrm{T}-\mathrm{NiFe}_{2} \mathrm{O}_{4}$ NPs. They were found to exhibit another absorption band at $365 \mathrm{~nm}$ in addition to the band at $325 \mathrm{~nm}$ as shown in Fig. 2(d). The surface modification is found to result in three photoluminescence peaks with many fold increase in overall intensity, upon
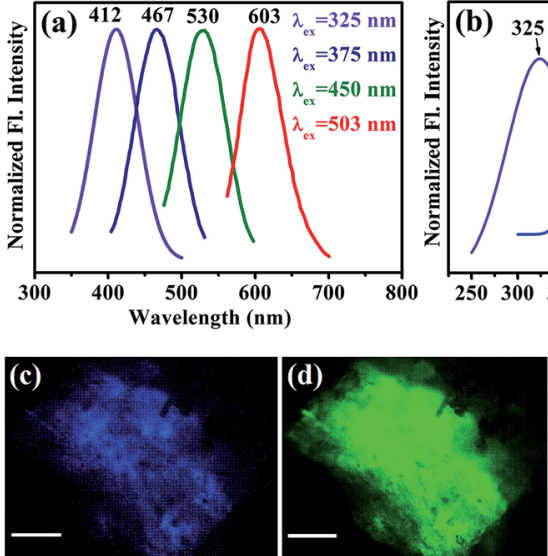

Fig. 3 (a) Normalized steady-state fluorescence emission spectra obtained from fluorescence-modified $\mathrm{T}-\mathrm{NiFe}_{2} \mathrm{O}_{4} \mathrm{NPs}$ after excitation at four different wavelengths, $\lambda_{\mathrm{ex}}=325,375,450$, and $503 \mathrm{~nm}$. (b) Fluorescence excitation spectra of fluorescence-modified $\mathrm{T}-\mathrm{NiFe}_{2} \mathrm{O}_{4}$ NPs at different emission maxima, that is, $\lambda_{\mathrm{em}}=412,467,530$, and $603 \mathrm{~nm}$. Fluorescence images of fluorescence-modified $\mathrm{T}-\mathrm{NiFe}_{2} \mathrm{O}_{4}$ NPs powder under (c) UV (375 nm), (d) blue (450 nm), and (e) green $(515 \mathrm{~nm}$ ) light irradiation. The scale bars in all images are $500 \mu \mathrm{m}$. excitation at proper wavelengths as shown in Fig. 3(a), the normalized steady state photoluminescence emission spectra of fl. mod. T- $-\mathrm{NiFe}_{2} \mathrm{O}_{4}$ NPs. This is due to an increase in the strength of the coordination between the functional groups of the ligand $\left(-\mathrm{COO}^{-}\right.$and $-\mathrm{OH}$ moieties) and the metal ion $\left(\mathrm{Ni}^{2+}\right)$ which leads to three more photoluminescence peaks as well as a huge increase in photoluminescence intensity of $\mathrm{T}-\mathrm{NiFe}_{2} \mathrm{O}_{4}$ NPs. Upon exciting with wavelengths of 325, 375, 450, and $503 \mathrm{~nm}$, the NPs solution gave rise to significant photoluminescence peaks at 412, 467, 530, and $603 \mathrm{~nm}$, respectively. These bands are clearly distinguishable also in the excitation study as shown in Fig. 3(b). The fluorescence micrographs of fl. mod. $\mathrm{T}-\mathrm{NiFe}_{2} \mathrm{O}_{4}$ NPs show the photoluminescent colors like blue (Fig. 3(c)), green (Fig. 3(d)) and red (Fig. 3(e)) on excitation of at 375,450 , and $515 \mathrm{~nm}$, respectively, by using proper filters for the excitation wavelengths.

The LFT efficiently explains the generation of multicolour photoluminescence. Based on the LFT a ligand co-ordination with the NPs' surface plays the key role, which yields the crystal field splitting energy (CFSE) $(\Delta)$ generated from d orbital splitting with a magnitude determined by the ligands and a given coordination symmetry. The strength of the metalligand $\sigma$ bond increases as a function of increasing basicity of the solution. As the basicity of the solution increases, the 2carboxyl and 2-hydroxyl groups become deprotonated resulting in larger interactions with the metal ions and as an outcome, CFSE $(\Delta)$ associated with the ligand increases which finally lead to an increased splitting between the previous degenerate d orbitals. The emission peaks at 467, 530 and $603 \mathrm{~nm}$ can be attributed to ${ }^{3} \mathrm{~A}_{2 \mathrm{~g}}(\mathrm{~F}) \rightarrow{ }^{3} \mathrm{~T}_{1 \mathrm{~g}}(\mathrm{P}),{ }^{3} \mathrm{~A}_{2 \mathrm{~g}}(\mathrm{~F}) \rightarrow{ }^{3} \mathrm{~T}_{1 \mathrm{~g}}(\mathrm{~F})$ and ${ }^{3} \mathrm{~A}_{2 \mathrm{~g}}$ (F) $\rightarrow{ }^{3} \mathrm{~T}_{2 \mathrm{~g}}$ (F) transitions involving $\mathrm{d}-\mathrm{d}$ orbitals of $\mathrm{Ni}^{2+}$ ions respectively, where these energy levels were obtained from the Tanabe Sugano diagram of $\mathrm{Ni}^{2+}$. These $\mathrm{d}-\mathrm{d}$ transitions are formally spin allowed transitions. Note that $d-d$ transitions involving only $\mathrm{Fe}^{3+}$ are not efficient for the development of intense fluorescence. ${ }^{22}$ On the other hand, due to strong ligand to metal charge transfer (LMCT) from HOMO (Highest Occupied Molecular Orbital, centered on the ligand) to LUMO (Lowest Unoccupied Molecular Orbital, centered on the metal ions), bonding interactions between the metal and the ligand increases considerably. Therefore, the photoluminescence peak arising at $412 \mathrm{~nm}$ can be attributed to LMCT involving HOMO of tartrate ligand and LUMO centered over metal ion $\mathrm{Ni}^{2+} \cdot{ }^{23}$ The Quantum Yield (QY) is calculated by taking rhodamine B (Rh B) as the standard fluorescent compound and the obtained QYs are $15.13 \%$ for the $412 \mathrm{~nm}$ band, $1.6 \%$ for the $467 \mathrm{~nm}$ band and the $0.15 \%$ for $530 \mathrm{~nm}$ band of fl. $\bmod$. T-NiFe $\mathrm{O}_{4}$ NPs.

In order to confirm the attachment of the tartrate molecules to the surface of $\mathrm{NiFe}_{2} \mathrm{O}_{4} \mathrm{NPs}$, we carried out the FTIR study of bare $\mathrm{NiFe}_{2} \mathrm{O}_{4} \mathrm{NPs}, \mathrm{T}-\mathrm{NiFe}_{2} \mathrm{O}_{4}$ NPs and pure tartrate ligand. As depicted in Fig. 4(a), the peak arising at $587 \mathrm{~cm}^{-1}$ is due to stretching vibration of metal-oxygen bonds in $\mathrm{NiFe}_{2} \mathrm{O}_{4}$. The peak at $587 \mathrm{~cm}^{-1}$ is absent in $\mathrm{T}-\mathrm{NiFe}_{2} \mathrm{O}_{4}$ NPs. Two sharp peaks arising at 1066 and $1112 \mathrm{~cm}^{-1}$ in the case of tartrate ligand are due to $\mathrm{C}-\mathrm{OH}$ stretching modes ${ }^{24}$ and two other peaks at 1411 and $1621 \mathrm{~cm}^{-1}$ are due to the symmetric and asymmetric stretching of the $\mathrm{COO}^{-} .^{25}$ In the case of $\mathrm{T}-\mathrm{NiFe}_{2} \mathrm{O}_{4} \mathrm{NPs}$, due to 

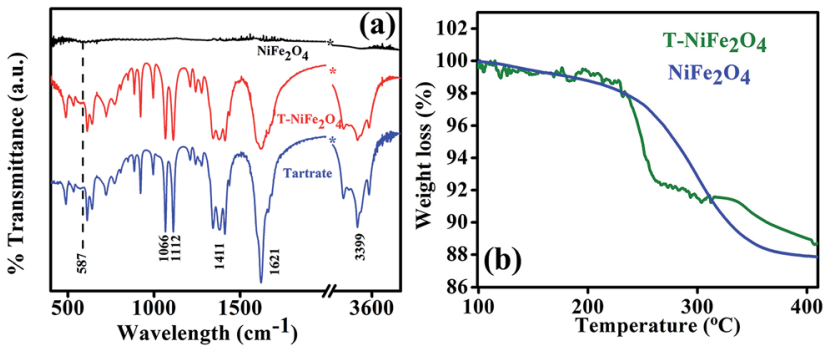

Fig. 4 (a) FTIR spectra of as-prepared $\mathrm{NiFe}_{2} \mathrm{O}_{4}$ and $\mathrm{T}-\mathrm{NiFe}_{2} \mathrm{O}_{4} \mathrm{NPS}$ together with pure $\mathrm{Na}$-tartrate, (b) TGA curve of as-prepared $\mathrm{NiFe}_{2} \mathrm{O}_{4}$ and $\mathrm{T}-\mathrm{NiFe}_{2} \mathrm{O}_{4} \mathrm{NPs}$.

the interactions between NPs surface and the functional group moieties of the ligand, all the bands are distinctly perturbed along with the band at $3399 \mathrm{~cm}^{-1}$ which arises because of the stretching vibrational modes of the $\mathrm{O}-\mathrm{H}$ group. ${ }^{24}$ This clearly indicates the involvement of $-\mathrm{COO}^{-}$and $-\mathrm{OH}$ group in the functionalization. thermogravimetric analysis (TGA) data of the as-prepared and tartrate functionalized Nickel ferrite measured under nitrogen atmosphere from 100 to $400{ }^{\circ} \mathrm{C}$ and shown in Fig. 4(b). The amount of tartrate ligand bound to the nanoparticle surface was calculated from the TGA data and found to be $\sim 1.88 \mathrm{wt} \%$ of the $\mathrm{T}-\mathrm{NiFe}_{2} \mathrm{O}_{4} \mathrm{NPs}$.

The room temperature magnetic behaviour of the as-

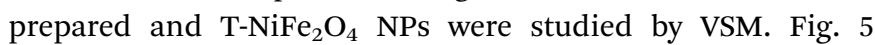
depicts the $M-H$ loops of both as-prepared and functionalized $\mathrm{NiFe}_{2} \mathrm{O}_{4}$ NPs. From Fig. 5(a) and (b) it is found that the saturation magnetization and coercivity are reduced from $37.1 \mathrm{emu}$ $\mathrm{g}^{-1}$ to $11.7 \mathrm{emu} \mathrm{g}^{-1}$ and from 0.04 kOe to $0.02 \mathrm{kOe}$, respectively, in case of $\mathrm{T}-\mathrm{NiFe}_{2} \mathrm{O}_{4} \mathrm{NPs}$ in comparison with as-prepared $\mathrm{NiFe}_{2} \mathrm{O}_{4}$ NPs. The tartrate ligand contains both $\sigma$ donor $(-\mathrm{OH})$ and $\pi$ donor $\left(-\mathrm{COO}^{-}\right)$groups which results in immense LMCT and spin pairing of $\mathrm{Ni}^{2+}$ ions in $\mathrm{T}-\mathrm{NiFe}_{2} \mathrm{O}_{4} \mathrm{NPs}$, which reduces the saturation magnetization. ${ }^{26}$

After efficiently incorporating the intrinsic fluorescence in $\mathrm{NiFe}_{2} \mathrm{O}_{4} \mathrm{NPs}$, we inspected the optical excitation of the functionalized $\mathrm{NiFe}_{2} \mathrm{O}_{4} \mathrm{NPs}$ in photocatalysis for waste water treatment. The functionalized $\mathrm{NiFe}_{2} \mathrm{O}_{4} \mathrm{NPs}$ were found to possess efficient photocatalytic properties (as shown in Fig. 6(a)). In case of the degradation of $\mathrm{MB}$, a frequently used dye in textile industries and a model water-contaminant, a catalytic effect occur after UV light irradiation. We found that the
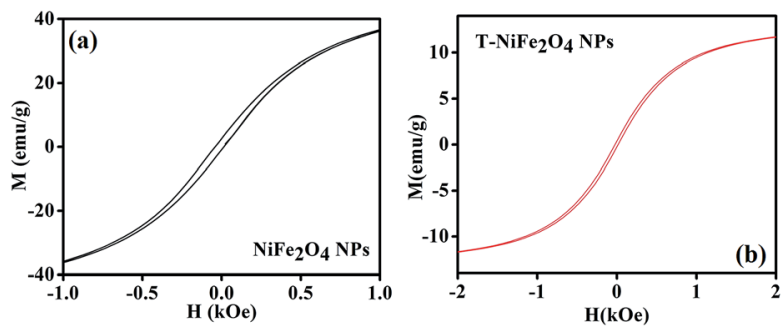

Fig. 5 (a) Plot of magnetization versus applied magnetic field $(M-H)$ of as-prepared $\mathrm{NiFe}_{2} \mathrm{O}_{4} \mathrm{NPs}$ at $300 \mathrm{~K}$, (b) $\mathrm{M}-\mathrm{H}$ plot for $\mathrm{T}-\mathrm{NiFe}_{2} \mathrm{O}_{4} \mathrm{NPs}$ at $300 \mathrm{~K}$.

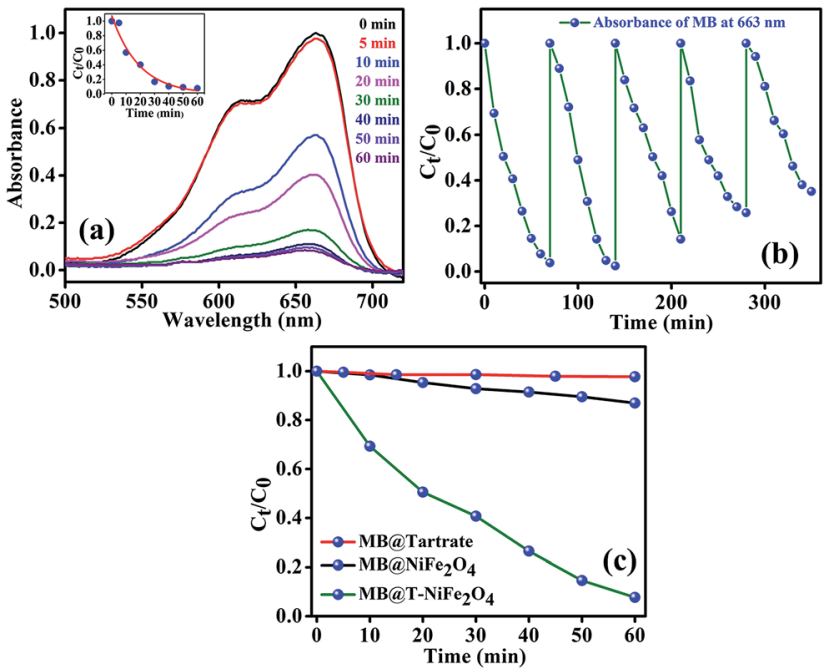

Fig. 6 (a) The UV/Vis spectral changes of an aqueous solution of MB in the presence of $\mathrm{T}-\mathrm{NiFe}_{2} \mathrm{O}_{4} \mathrm{NPs}$ with time, under UV irradiation, (inset of (a) fitted first order reaction rate), (b) plots of relative concentration of MB monitored at $663 \mathrm{~nm}$ versus time for five consecutive cycles, showing reusability of $\mathrm{T}-\mathrm{NiFe}_{2} \mathrm{O}_{4} \mathrm{NPS}$ in $\mathrm{MB}$ degradation under UV light, (c) the rate of photocatalytic degradation of $\mathrm{MB}$ (monitored at $663 \mathrm{~nm}$ ) in presence of $\mathrm{Na}$-tartrate, $\mathrm{NiFe}_{2} \mathrm{O}_{4}$ and $\mathrm{T}-\mathrm{NiFe}_{2} \mathrm{O}_{4} \mathrm{NPs}$.

photodegradation of $\mathrm{MB}$ in presence of functionalized $\mathrm{NiFe}_{2} \mathrm{O}_{4}$ $\mathrm{NPs}$ at $\mathrm{pH} \sim 3$ takes place exponentially with time following a first-order rate equation (by fitting with equation $A=A_{0} \mathrm{e}^{-k t}$ ) with a kinetic rate constant $k=2.82 \times 10^{-2} \mathrm{~min}^{-1}$. We also carried out a reusability test of the catalyst with $70 \mathrm{~min}$ of time interval as shown in Fig. 6(b). We kept adding MB up to 5 cycles by keeping the concentration of the catalyst same (by not adding more catalyst after the $1^{\text {st }}$ cycle). We measured the decomposition rate of the MB by monitoring the absorbance at $663 \mathrm{~nm}$ by UV/Vis spectroscopy that had led to conclude the reusability of T- $\mathrm{NiFe}_{2} \mathrm{O}_{4}$ NPs as a catalyst. The comparative rate of degradation of MB by Na-tartrate, bare $\mathrm{NiFe}_{2} \mathrm{O}_{4} \mathrm{NPs}$ and $\mathrm{T}-\mathrm{NiFe}_{2} \mathrm{O}_{4}$ NPs is shown in Fig. 6(c).

Stimulated by the photocatalytic property of the functionalized $\mathrm{NiFe}_{2} \mathrm{O}_{4}$ NPs on MB, we have performed similar experiment on a biologically toxic pigment, $\mathrm{BR}$ which is responsible for the occurrence of yellow coloration of skin in jaundice. T$\mathrm{NiFe}_{2} \mathrm{O}_{4} \mathrm{NPs}$ shows a good catalytic activity in the degradation of $\mathrm{BR}$ without any photoexcitation at $\mathrm{pH} \sim 7$ at room temperature as shown in Fig. 7(a). The reaction follows first order kinetics with the reaction rate constant $k=6.5 \times$ $10^{-3} \mathrm{~min}^{-1}$. We investigated the recyclability of the catalytic efficiency of T-NiFe $\mathrm{O}_{4}$ for degradation of BR by adding the same amount of BR to the reaction mixture in every $60 \mathrm{~min}$ up to 3 cycles, keeping the concentration of the catalyst unchanged. We measured the fall in absorbance of the BR at $435 \mathrm{~nm}$ at regular intervals by UV/Vis spectroscopy. The plot of relative BR concentration as a function of time for up to three consecutive cycles, as demonstrated in Fig. 7(b), confirms the reusability of the T- $\mathrm{NiFe}_{2} \mathrm{O}_{4}$ NPs catalyst. Fig. 7 (c) depicts the rate of degradation of BR by Na-tartrate, bare $\mathrm{NiFe}_{2} \mathrm{O}_{4} \mathrm{NPs}$ and T-NiFe ${ }_{2} \mathrm{O}_{4}$ NPs. 

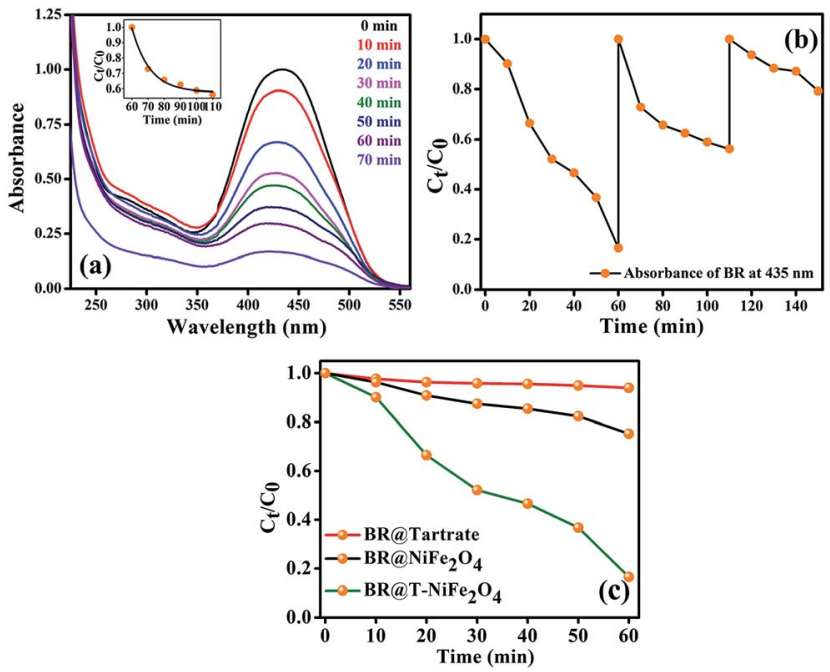

Fig. 7 (a) The UV/Vis spectral changes of an aqueous solution of BR in the presence of $\mathrm{T}-\mathrm{NiFe}_{2} \mathrm{O}_{4} \mathrm{NPs}$ with time, (inset of (a) fitted first order reaction rate) (b) plots of the relative concentration of $B R$ monitored at $435 \mathrm{~nm}$ versus time for three consecutive cycles, showing reusability of $\mathrm{T}-\mathrm{NiFe}_{2} \mathrm{O}_{4} \mathrm{NPs}$ in the degradation of $\mathrm{BR}$, (c) the rate of catalytic degradation of $\mathrm{BR}$ (monitored at $435 \mathrm{~nm}$ ) in presence of $\mathrm{Na}$-tartrate, $\mathrm{NiFe}_{2} \mathrm{O}_{4}$ and $\mathrm{T}-\mathrm{NiFe}_{2} \mathrm{O}_{4} \mathrm{NPs}$.

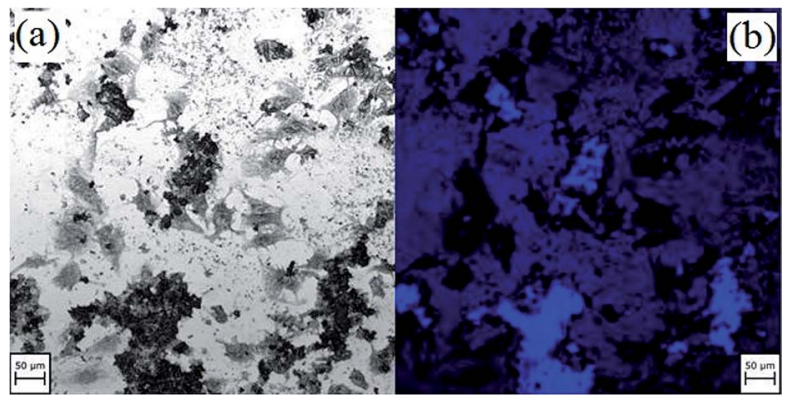

Fig. 8 Osteosarcoma cells with $\mathrm{T}-\mathrm{NiFe}_{2} \mathrm{O}_{4} \mathrm{NPs}$ at a concentration of $2 \mathrm{mg} \mathrm{mL}^{-1}$ cell medium in (a) bright field and (b) LSM with an excitation wavelength of $370 \mathrm{~nm}$.

Fig. 8 shows human osteosarcoma cells in the presence of culture medium with a NP concentration of $2 \mathrm{mg} \mathrm{mL}^{-1}$. From Fig. 8(a) it can be deduced that the cells are alive and in a good condition indicating the non-toxicity of the NPs. Fig. 8(b) shows that NPs adhere to cells and fluoresce under illumination with light of appropriate wavelength and intensity.

\section{Conclusions}

Through easy surface modification of $\mathrm{NiFe}_{2} \mathrm{O}_{4}$ NPs with Natartrate ligands, we have prepared biocompatible multifunctional nanoparticles with intrinsic fluorescence properties covering the whole visible region, ranging from blue, and green, to red. The NPs are found to be efficient in cell imaging using this inherent fluorescent property. Additionally, the $\mathrm{T}-\mathrm{NiFe}_{2} \mathrm{O}_{4}$ NPs show good catalytic and photocatalytic activity in the degradation of biologically and environmentally toxic pigments [bilirubin and methylene blue] respectively. A thorough experimental and theoretical study has revealed that the LMCT transition from the highest occupied energy level of the tartrate ligand to lowest unoccupied energy levels of $\mathrm{Ni}^{2+}$ and $\mathrm{d}-\mathrm{d}$ transitions centered over $\mathrm{Ni}^{2+}$ ions on the NPs' surface play crucial roles in the generation of multicolor fluorescence from the $\mathrm{T}$ $\mathrm{NiFe}_{2} \mathrm{O}_{4}$ NPs. We trust that the development of these multifunctional $\mathrm{T}-\mathrm{NiFe}_{2} \mathrm{O}_{4}$ NPs will open new opportunities in the field of diagnostics, such as bio-imaging, therapeutics and drug delivery, as well as in wastewater treatment of contaminants.

\section{Conflicts of interest}

There are no conflicts to declare.

\section{Acknowledgements}

Authors like to thank Mr Samik Roy Moulik, Ms Urmi Chakraborty and Mr Dipankar Roy for performing TEM, TGA and VSM measurements, respectively. Financial support to one of the authors (K. M.) from Alexander von Humboldt Foundation, Germany is gratefully acknowledged.

\section{References}

1 L. H. Reddy, J. L. Arias, J. Nicolas and P. Couvreur, Chem. Rev., 2012, 112, 5818-5878.

2 A. K. Gupta and M. Gupta, Biomaterials, 2005, 18, 3995-4021.

3 R. Rakshit, M. Pal, A. Chaudhuri and K. Mandal, APL Mater., 2015, 3, 110701-110706.

4 M. Colombo, S. Carregal-Romero, M. F. Casula, L. Gutiérrez, M. P. Morales, I. B. Böhm, J. T. Heverhagen, D. Prosperi and W. J. Parak, Chem. Soc. Rev., 2012, 41, 4306-4334.

5 F. Yang, Y. Li, Z. Chen, Y. Zhang, J. Wu and N. Gu, Biomaterials, 2009, 30, 3882-3890.

6 H. B. Na, I. C. Song and T. Hyeon, Adv. Mater., 2009, 21, 2133-2148.

7 O. Veiseh, J. W. Gunn and M. Zhang, Adv. Drug Delivery Rev., 2010, 62, 284-304.

8 M. Liong, J. Lu, M. Kovochich, T. Xia, S. G. Ruehm, A. E. Nel, F. Tamanoi and J. I. Zink, ACS Nano, 2008, 2, 889-896.

9 D. L. J. Thorek, A. K. Chen, J. Czupryna and A. Tsourkas, Ann. Biomed. Eng., 2006, 34, 23-38.

10 M. Tamura, F. Yanagawa, S. Sugiura, T. Takagi, K. Sumaru, H. Matsui and T. Kanamori, Sci. Rep., 2014, 4, 4793-4798.

11 N. Tran and T. J. Webster, Wiley Interdiscip. Rev.: Nanomed. Nanobiotechnol., 2009, 1, 336-351.

12 M. Johannsen, U. Gneveckow, L. Eckelt, A. Feussner, N. Waldöfner, R. Scholz, S. Deger, P. Wust, S. A. Loening and A. Jordan, Int. J. Hyperthermia, 2005, 21, 637-647.

13 Y. Li, H. Tan, X. Y. Yang, B. Goris, J. Verbeeck, S. Bals, P. Colson, R. Cloots, G. V. Tendeloo and B. L. Su, Small, 2011, 7, 475-483.

14 P. Zhang, Y. Zhan, B. Cai, C. Hao, J. Wang, C. Liu, Z. Meng, Z. Yin and Q. Chen, Nano Res., 2010, 3, 235-243.

15 M. B. Gawande, V. D. B. Bonifacio, R. S. Varma, I. D. Nogueira, N. Bundaleski, C. A. A. Ghumman, 
O. M. N. D. Teodoro and P. S. Branco, Green Chem., 2013, 15, 1226-1231.

16 M. B. Gawande, A. K. Rathi, I. D. Nogueira, R. S. Varma and P. S. Branco, Green Chem., 2013, 15, 1895-1899.

17 M. B. Gawande, P. S. Branco and R. S. Varma, Chem. Soc. Rev., 2013, 42, 3371-3393.

18 M. Pal, A. K. Singh, R. Rakshit and K. Mandal, RSC Adv., 2015, 5, 16311-16318.

19 M. Pal, R. Rakshit and K. Mandal, Appl. Phys. Lett., 2014, 104, 233110-233114.

20 X. Ren, L. Tong, X. Chen, H. Ding, X. Yang and H. Yang, Phys. Chem. Chem. Phys., 2014, 16, 10539-10547.
21 S. Sun, H. Zeng, D. B. Robinson, S. Raoux, P. M. Rice, S. X. Wang and G. Li, J. Am. Chem. Soc., 2004, 126, 273-279.

22 J. E. Huheey, E. A. Keiter, R. L. Keiter and O. K. Medhi, Inorganic Chemistry: Principles of Structure and Reactivity (Fourth Edition), Pearson Education, 2006.

23 M. Pal, R. Rakshit and K. Mandal, ACS Appl. Mater. Interfaces, 2014, 6, 4903-4910.

24 N. Kaneko, M. Kaneko and H. Takahashi, Spectrochim. Acta, Part A, 1984, 40, 33-42.

25 V. Ramakrishnan and J. M. T. Maroor, Infrared Phys., 1988, 28, 201-204.

26 R. Rakshit, M. Pal, M. Mandal and K. Mandal, Mater. Lett., 2015, 151, 64-67. 